\title{
Paisagem linguística como instrumento de políticas linguísticas em uma colônia de imigração suábia/alemã
}

\author{
Adriana Dalla Vecchia \\ Universidade Estadual de Maringá (UEM), Maringá, Paraná, Brasil \\ adrianarevisao@gmail.com
}

DOI: http://dx.doi.org/10.21165/el. v45i2.652

\begin{abstract}
Resumo
Este trabalho objetiva demonstrar a paisagem linguística de uma colônia de imigração suábia/alemã do interior do Paraná, a fim de compreender a forma como as línguas presentes no local são disponibilizadas e representadas em espaços públicos da colônia. Além disso, entendendo a paisagem linguística como instrumento de política linguística, discutimos como esse instrumento atua sobre a construção da identidade étnica e linguística do grupo. Trata-se,portanto, de uma pesquisa qualitativa, de cunho etnográfico aos moldes da proposta de Blommaert (2010). O material coletado é analisado a partir da ótica teórico-metodológica proveniente do campo das Paisagens Linguísticas (BLOMMAERT, 2006, 2012, 2013; SHOHAMY, 2012), e de estudos sobre contextos plurilíngues (MAHER, 1996, 2010, 2013; ASSIS-PETERSON, 2008).
\end{abstract}

Palavras-chave: paisagem linguística; políticas linguísticas; políticas de identidade.

\section{Linguistic Landscape as a Tool for Linguistic Policies in a Swabian/German Immigration Colony}

\begin{abstract}
This study aims to demonstrate the linguistic landscape of a Swabian/German immigration colony in Paraná state and to understand how the local languages are available and represented in public spaces within the colony. In addition, by understanding linguistic landscape as a language policy instrument, it is discussed how this tool works on the construction of the ethnic and linguistic identity of the group. This is an ethnographic qualitative research, according to Blommaert (2010). The collected material is analyzed under the theoretical and methodological perspective from the field of linguistic landscapes (BLOMMAERT, 2006, 2012, 2013; SHOHAMY, 2012), and studies on multilingual contexts (MAHER, 1996, 2010, 2013; ASSIS-PETERSON, 2008).
\end{abstract}

Keywords: linguistic landscape; language policies; identity politics.

\section{Introdução}

Nas práticas de linguagem, nesse mundo globalizado, há muitos usos transidiomáticos (JACQUEMET, 2005) e processos transglóssicos (ASSIS-PETERSON, 2008), os quais são vistos como reflexos do mundo superdiverso e complexo (VERTOVEC, 2007; BLOMMAERT, 2012) que tem se consolidado e expandido desde o fim da Guerra Fria. A superdiversidade se refere ao panorama de diversidade social, cultural e econômica enquanto efeito do modo como as pessoas e as sociedades organizam suas vidas, cuja base está na mobilidade, na complexidade e na imprevisibilidade (BLOMMAERT, 2012). Dentro desse universo, a língua tem uma posição privilegiada, uma vez que por meio dela torna-se possível detectar algumas características da superdiversidade. 
Sob essa ótica, muitos trabalhos vêm sendo desenvolvidos para dar visibilidade a ambientes superdiversos, e um dos caminhos percorridos baseia-se nas considerações sobre paisagens linguísticas. Tais estudos, em geral, documentam ambientes globalizados e pós-modernos, no entanto, como alertam Blommaert e Maly (2014), também são documentados lugares menos urbanos, periféricos e/ou espaços rurais, com menor índice de plurilinguismo. Embora esses lugares sejam raros, podem apresentar características da superdiversidade e oferecer oportunidades de estudo mostrando que um ambiente pretensamente monolíngue pode ser plurilíngue.

Nesse aspecto, o Brasil é um caso exemplar: são cerca de 222 línguas faladas no país como línguas maternas de cidadãos brasileiros. Destas, 180 são indígenas, 40 são de imigração e duas de sinais (LIBRAS - Língua Brasileira de Sinais e a Língua de Sinais Kaapor Brasileira) (OLIVEIRA, 2003). Assim, de certo modo, podemos considerar o Brasil como um país superdiverso e plurilíngue. Sua caracterização como plurilíngue, porém, torna-se mais visível ao se considerar os contextos sociolinguisticamente complexos espalhados ao longo do seu território. Conforme Maher (2013, p. 128) afirma, olhar de forma rápida sobre "o modo como a paisagem linguística brasileira se configura, hoje, revela algumas das maneiras como falantes [...] das línguas tornadas minoritárias no país vêm se mobilizando para torná-las visíveis, ajudando a mudar/moldar a ecologia linguística do país" e a ver o lugar como superdiverso. Esses ambientes não são densamente plurilíngues, mas carregam a complexidade em suas práticas linguísticas e são de extrema importância para dissipar o mito do monolinguismo brasileiro.

A partir dessa orientação, destacamos que este trabalho tem como objetivo descrever a paisagem linguística de uma colônia de imigração suábia/alemã do interior do Paraná, ambiente caracteristicamente plurilíngue Schwowisch/Português/Hochdeutsch, a fim de compreender a forma como essas línguas são disponibilizadas e representadas em espaços públicos da colônia, investigando se a paisagem linguística local revela as estratégias dos falantes das línguas em contato para torná-las visíveis, ou seja, como têm atuado na moldagem da ecologia linguística da região. Além disso, entendendo a paisagem linguística como instrumento de política linguística, discutimos sobre como ele atua na construção da identidade étnica e linguística do grupo.

Para tanto, optamos pela realização de uma pesquisa qualitativa, de cunho etnográfico aos moldes da proposta de Blommaert (2010), na qual são registrados fotograficamente os hábitos de uma comunidade e/ou as suas ocorrências linguísticas. $\mathrm{O}$ material coletado é analisado a partir da perspectiva teórico-metodológico proveniente do campo das Paisagens Linguísticas (BLOMMAERT, 2006, 2012, 2013; SHOHAMY, 2012), bem como considerando estudiosos que se ocupam da caracterização de contextos sociolinguisticamente complexos (MAHER, 1996, 2010, 2013; ASSIS-PETERSON, 2008; CAVALCANTI, 2015).

\section{Paisagem linguística como campo de estudo}

O estudo das Paisagens Linguísticas (Linguistic Landscapes) vem se expandindo na última década (BLOMMAERT, 2012; MAHER, 2013) e ganhando espaço em trabalhos dedicados ao plurilinguismo. Essa perspectiva surge, segundo Blommaert e Maly (2014), a partir da tentativa de se fazer inventários apurados e detalhados do multilinguismo urbano. Assim, os estudos dessa área procuram entender como as línguas são disponibilizadas e representadas em locais e espaços públicos, permitindo a 
compreensão acerca das funções de cada língua naquele contexto (MAHER, 2013; BLOMMAERT, 2012).

Para Cenoz e Gorter (2008b), estudar a Paisagem Linguística é observar as línguas no contexto em que são utilizadas, centrando-se na informação escrita que está disponível em uma área específica. As informações escritas podem estar em indicações de trânsito, painéis publicitários, nomes de ruas, nomes de lugares, letreiros de estabelecimentos comerciais, ou seja, em todo material linguístico que contribui para a construção do cenário linguístico de um dado território, região ou aglomeração urbana. Para Cenoz e Gorter (2008a, p. 1), 'the 'linguistic landscape' refers to all the language items that are visible in a specified part of the public space."

A paisagem linguística ao mesmo tempo reflete e afeta a situação linguística da cidade, região ou território porque a relação entre as línguas presentes no cenário linguístico pode ser um fator muito importante na promoção do uso de determinada língua. Dessa forma, a paisagem linguística pode ser responsável, dentre outros fatores, por processos de manutenção e mudança de língua (CENOZ; GORTER, 2008b), contribuindo para a construção do contexto sociolinguisticamente complexo, uma vez que as pessoas processam a informação visual nas línguas em que são escritos os textos a que têm acesso, deixando-se influenciar no modo como percebem as diferentes línguas, o que pode afetar o seu comportamento linguístico (CENOZ; GORTER, 2006, p. 68). Muitas vezes, quando se quer promover determinada língua, a paisagem linguística colabora com essa ação, influenciando o uso dessa língua.

Segundo Cenoz e Gorter (2006; 2008b), as funções da paisagem, então, podem ser de dois tipos: informativa ou simbólica. A informativa se refere ao fato de que as línguas usadas indicam as fronteiras do território habitado por um grupo linguístico e também a disponibilidade de os falantes de um grupo interagirem por meio daquelas línguas na região. Nesse sentido, a Paisagem Linguística é uma fonte adicional de informações sobre o contexto sociolinguístico juntamente com censos, pesquisas ou entrevistas e, ainda, indicadora do plurilinguismo. A função simbólica, por sua vez, está relacionada à percepção que os membros de um grupo linguístico têm do valor e do status das línguas presentes em um contexto, em comparação com outras línguas. Essas informações sobre o contexto podem ser comparadas à política linguística oficial da região para pensar como se constrói o status e o poder das línguas na região.

Vale dizer que as características da análise das paisagens linguísticas colocam o foco dos estudos não no espaço físico, mas no espaço social. Para melhor esclarecimento, destaca-se que o espaço físico passa a ser social quando "permite, empele, convida, prescreve, proscreve políticas ou impõe certos padrões de comportamento social; [...] sempre espaço de alguém; um espaço histórico, portanto, cheio de códigos, expectativas, normas e tradições; e um espaço de poder controlado por [...]" (BLOMMAERT, 2012, p. $8)$.

Pensando o espaço como aquilo que é histórico, social e cultural, compreende-se que ele pode fornecer informações sobre as diferenças entre a política oficial de uso de língua, em contraposição às políticas linguísticas regionais pela presença da língua oficial ao lado de/em sobreposição/em posição inferior à língua local. No caso de contextos sociolinguisticamente complexos no Brasil, em geral, há uma ou duas línguas majoritárias e uma ou duas minoritarizadas ${ }^{1}$, e a relação entre elas pode ser observada na paisagem

\footnotetext{
${ }^{1}$ Os contextos sociolinguisticamente complexos, em geral, contam com variedades desprestigiadas de uma mesma língua ou mais de uma língua além da oficial. Essas línguas e variedades não são por si mesmas inferiorizadas, mas são vistas assim pelos falantes da língua dominante, ou seja, são minoritarizadas por
} 
linguística. Dessa maneira, as minoritarizadas, ao serem expostas em locais públicos, ganham espaços importantes para a sua sobrevida e fortalecimento, conforme mostra Blommaert (2012). Embora isso possa acontecer, é mais possível que a língua maioritária de uma comunidade linguística seja utilizada com mais frequência em espaços públicos do que a língua minoritária (CENOZ; GORTER, 2006).

Cenoz e Gorter $(2006 ; 2008 b)$ mostram que a paisagem linguística sempre é um efeito da política linguística adotada pelas autoridades estaduais e regionais, as quais decidem incluir sinalização em uma ou mais línguas com objetivos bem claros. De acordo com os autores, nesses casos, geralmente há uma política linguística bem desenvolvida para o uso das línguas na mídia ou na educação. Assim, estão implicados na paisagem linguística não somente o signo em línguas diferentes, mas a forma como as pessoas se relacionam com materiais dispostos nos locais públicos (SHOHAMY, 2012).

Esse tipo de pesquisa tem mostrado que nem sempre as línguas presentes na paisagem linguística correspondem às línguas usadas no dia-a-dia pelos integrantes de determinada comunidade. Isso indica que a paisagem é o lugar, como observa Shohamy (2012), de construção simbólica do espaço público e não necessariamente um retrato dos usos reais de línguas, constituindo-se, portanto, como uma arena onde ideologias e políticas se enfrentam.

\section{$O$ contexto de pesquisa e sua paisagem linguística}

\section{Colônia Entre Rios}

Este estudo investiga um contexto sociolinguisticamente complexo Schwowisch/Português/Hochdeutsch, situado no interior do Paraná, na região centro-sul, próximo à cidade de Guarapuava. Trata-se da comunidade de imigração alemã/suábia de Entre Rios, erigida a partir de 1950, tornando-se distrito do município. Esse contexto, denominado pelos próprios habitantes e moradores do entorno como "colônia", foi construído pelos suábios do Danúbio, povo de origem germânica, provenientes de países como Hungria, Romênia e Iugoslávia. Nessa época, o Governo do Paraná concedeu o território paranaense aos imigrantes e, em contrapartida, recebeu o cultivo de trigo, para o qual os suábios do Danúbio tinham habilidades e técnicas. As construções na colônia iniciaram em 1950 e seus habitantes chegaram a partir de 1951. O grupo que desembarcou no Paraná era constituído por 500 famílias, totalizando 2.500 pessoas, e veio em busca de melhores condições de vida, pois, na Europa, perderam seu território devido à II Grande Guerra.

Antes de essas famílias chegarem, entretanto, segundo Elfes (1971), veio, em 1950, uma comissão, hoje chamada de grupo pioneiro, composta por um engenheiro agrônomo perito em cooperativas na Áustria e um padre, acompanhados por um sacerdote baiano, responsável pela tradução. Essa comissão visitou Goiás e algumas regiões do Paraná, a fim de verificar o melhor lugar para a instalação da colônia e acabou escolhendo o interior do Paraná, já que as terras da região paranaense, mesmo sendo ácidas e pobres em matéria orgânica, se localizavam entre dois rios, Jordão e Pinhão, e se mostravam ricas em minerais nutritivos, facilitando um pouco a implantação da colônia, bem como o início da agricultura.

A área foi dividida em cinco vilas, hoje chamadas de colônias pelos moradores da região, as quais foram loteadas, ficando a menos de dez quilômetros uma das outras,

outrem. Embora, em alguns contextos, possamos ter uma língua considerada minoria em número de falantes, ela pode ser maioria pelo status que angaria socialmente. (CAVALCANTI, 1999) 
formando um pentágono. As colônias, segundo Elfes (1971), receberam a denominação dos antigos locais sobre os quais foram estabelecidas: Vitória (centro administrativo, lugar das principais indústrias; posteriormente sede da escola particular e de uma escola estadual; centro social e médico); Jordãozinho, Cachoeira, Socorro e Samambaia (vilas residenciais com pouca atividade comercial).

No período de construção, o "planejamento, preparativos e construção da colônia de Entre Rios foram sustentados principalmente pelo governo suíço e pelo governo estadual paranaense, bem como por comerciantes suíços e brasileiros e bancos brasileiros" (ELFES, 1971, p. 57). Assim que houve possibilidade, buscando suprir a falta de rendimentos, os imigrantes fundaram uma cooperativa, em 6 de maio de 1951, "[a] fim de que houvesse também uma representação dos interesses danúbios-suábios para negociações oficiais, bancárias e com os comitês de auxílio" (ELFES, 1971, p. 46). Além de suprir essa necessidade urgente, a cooperativa, desde sua fundação, passou também a trabalhar em prol de outros dois objetivos bastante importantes para a comunidade: a produção agroindustrial e a preservação da cultura dos suábios do Danúbio.

O principal objetivo da implantação da cooperativa foi econômico, em prol do sustento da comunidade, mas ela também tem um papel importante no que se refere à cultura e à língua dos suábios do Danúbio, pois apoia grupos folclóricos que divulgam a dança típica dos suábios, investindo em ações e instituições que se responsabilizam por propagar a cultura da Antiga Pátria. É o caso do museu, fundado em 1971, do centro cultural, em funcionamento desde 1992, e do colégio, criado em 1968. Cada um desses centros propagadores da cultura suábia, bem como a instituição escolar, que inclui o ensino do alemão oficial (Hochdeutsch) recebem investimentos significativos de tempos em tempos da cooperativa.

O colégio, em especial, constitui-se, desde sua origem, como uma instituição particular que atende principalmente os filhos dos imigrantes e respectivos descendentes, oferecendo-lhes o ensino de todas as disciplinas comumente ensinadas em escolas brasileiras com o acréscimo da língua alemã. Apesar de a escola, inicialmente ter sido criada para atender os filhos dos imigrantes, aos poucos foi recebendo alunos não descendentes de suábios, pois a queda na taxa de natalidade desse povo ao longo dos anos propiciou um gradativo esvaziamento da instituição. Ou seja, o número de descendentes de suábios em idade escolar passou a não ser suficiente para manter a escola em funcionamento. Atualmente, a instituição atende também os alunos moradores da região não descendentes de suábios, bem como alunos provenientes da sede do município - estes em bem menor número. O colégio oferece níveis de escolaridade desde a Educação Infantil (Jardim de Infância) até o Ensino Médio, bem como cursos técnicoprofissionalizantes.

Os imigrantes que aqui aportaram tinham/têm como língua de interação uma variedade de língua alemã denominada por eles de Schwowisch. Ao se estabelecerem na região, a maioria dos imigrantes e seus primeiros descendentes passaram a falar português, além do Schwowisch. Atualmente, há mais falantes bilíngues Hochdeutsch/português do que monolíngues em Schwowisch, embora ainda haja falantes monolíngues nesta língua - alguns imigrantes da primeira geração (DALLA VECCHIA, 2013; OLIVEIRA, K. P., 2013). Essa nova configuração se explica pela atuação do colégio principalmente, conforme veremos a seguir.

A cooperativa local mantém contatos profissionais com a Alemanha e, por isso, exige que seus colaboradores de linha de frente saibam o Hochdeutsch, acreditando que esta língua favorece(rá) o contato mais amplo com aquele país. Com isso, acredita-se que 
o Schwowisch é apenas um dialeto, não uma língua que pode ser usada e ensinada na escola $^{2}$ e, assim, o Hochdeutsch é eleito como língua usada e ensinada na escola juntamente com o português. Essas características construíram e continuam a construir uma realidade linguística bastante específica na região.

\section{O papel da paisagem linguística da região}

$\mathrm{O}$ estudo da paisagem linguística do local mostrou-se uma ferramenta útil para caracterizar o regime sociolinguístico da área. De acordo com Blommaert (2012), essa abordagem permite um diagnóstico mais preciso no sentido de que descreve a realidade investigada, partindo do espaço social onde ocorre o fenômeno linguístico para chegar às considerações próprias do objetivo geral da pesquisa. Nesse caso, é de suma importância entender o uso das línguas em textos escritos dispostos pela região, contrapondo tais informações com a realidade linguística dos falantes plurilíngues.

No local são faladas três línguas, Schwowisch, Hochdeutsch e Português em domínios diferenciados, por exemplo: as línguas do colégio e da cooperativa são o Português e o Hochdeutsch; o Schwowisch é utilizado em situações informais, em família, entre amigos, mas preterida em situações formais e de prestígio. Salientamos que o Schwowisch, que não tem escrita oficializada, é considerado pelos falantes locais como dialeto, e não como língua, não podendo, por esse motivo, ocupar lugares e práticas de interação formais orais e/ou escritas. Nas placas que veremos a seguir, temos a presença do português em destaque e do Hochdeutsch em segundo plano, traduzindo a expressão em português, mostrando a coexistência dessas duas línguas. Seguem os primeiros exemplos:

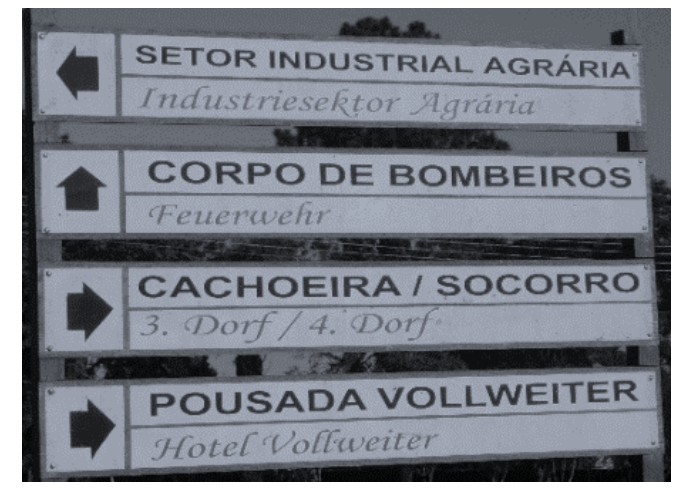

Figura 1. Placa indicativa de lugar (Fonte: acervo pessoal)

\footnotetext{
2 Esse trecho em itálico representa uma fala bastante comum dos participantes de uma pesquisa anterior, realizada entre os anos 2011 e 2013, também relativa a Entre Rios (DALLA VECCHIA, 2013).
} 


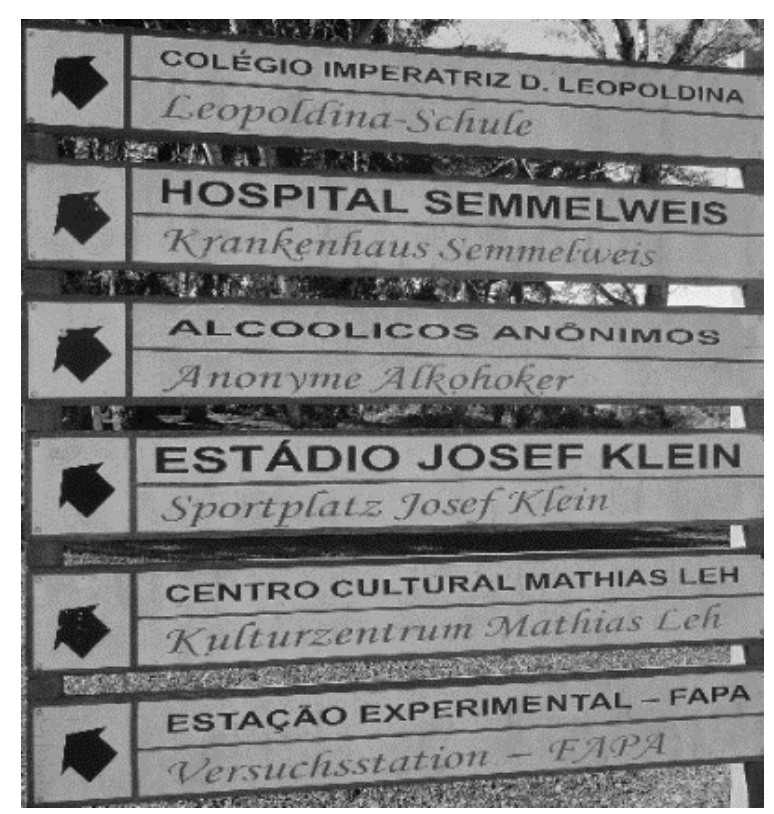

Figura 2. Placa indicativa de lugar (Fonte: acervo pessoal)

Nas cinco colônias, há placas como as das figuras 1 e 2 para indicação de espaços e instituições. Como se pode ver, há a denominação em português primeiramente e logo abaixo a versão em Hochdeutsch, grafada em itálico. Essa configuração se verá em todas as figuras analisadas neste texto, o que nos mostra que o Hochdeutsch tem presença forte na Colônia Entre Rios de modo geral, sendo parte da paisagem linguística, assim como o português. Essa presença parece-nos pedagógica no sentido de que acompanha a versão da expressão em português a qual é escrita em fonte maior, principalmente nesse tipo de placas - as indicativas.

Acreditamos que essa função pedagógica relaciona-se com a atuação do colégio da comunidade que tem o Hochdeutsch ensinado como língua estrangeira. A língua alemã na escola é ensinada por meio da língua portuguesa, nos primeiros anos de formação, no entanto, se a turma em questão recebe alunos falantes monolíngues de Schwowisch, os docentes acabam usando o Schwowisch até que a criança possa interagir em português e/ou em Hochdeutsch. Seguindo essa mesma linha de raciocínio, o uso da língua portuguesa nas placas seria uma orientação sobre como se referir às localizações nas duas línguas citadas. Isso vale para quem não sabe essa língua e como um reforço para aqueles que estão em formação no conhecimento dela.

Pela observação da paisagem linguística da região, podemos afirmar que todas as placas oficiais criadas pela própria comunidade com funções distintas - sejam placas indicativas (figuras 1 e 2), outdoors (figuras 3 e 4), placas com nomes de ruas em homenagem a personalidades importantes na história da comunidade, ou placas de monumentos - possuem a mesma estrutura: versões em português e em Hochdeutsch. Contatamos ainda que essas placas são de responsabilidade da própria comunidade, representada pela Cooperativa Agrária, ou seja, é a Cooperativa quem decide quais placas devem ser expostas e como devem ser estruturadas.

O município de Guarapuava, do qual Entre Rios é distrito, tem pouca expressividade nas decisões sobre o espaço da colônia, tanto que quase não há placas que sigam o mesmo padrão do município. Nesse sentido, vemos um trabalho voltado para a diferenciação entre a colônia e Guarapuava: a colônia é um espaço bilíngue português/Hochdeutsch, onde há imigrantes alemães. Usamos aqui o termo "alemães" com o propósito de trazer para discussão o imaginário dos guarapuavanos sobre a colônia. 
Para eles, trata-se de uma colônia de alemães, talvez por desconhecimento de que, no local, há descendentes de outros povos germânicos que não apenas alemães propriamente ditos, conforme vimos acima. Acreditamos que os moradores de Guarapuava utilizam essa denominação para Entre Rios em grande parte também pela paisagem linguística da região.

Para dar continuidade à discussão, seguem mais dois exemplares do espaço público da região. Agora são os outdoors de entrada e saída de Entre Rios, os quais também são estruturados em língua portuguesa e em Hochdeutsch.

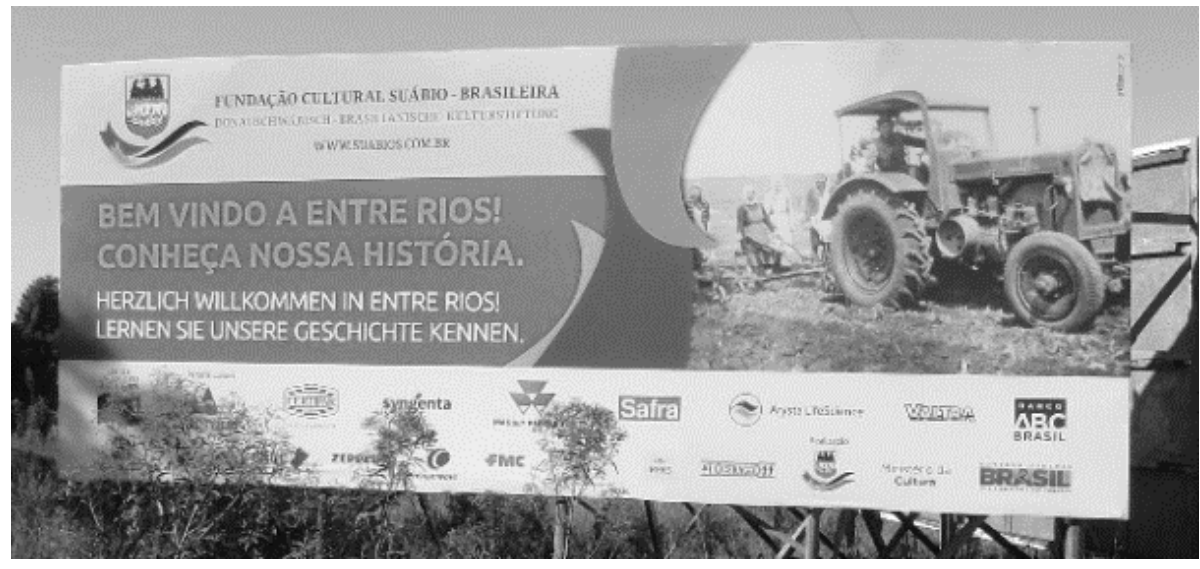

Figura 3. Placa de entrada de Entre Rios (Fonte: acervo pessoal)

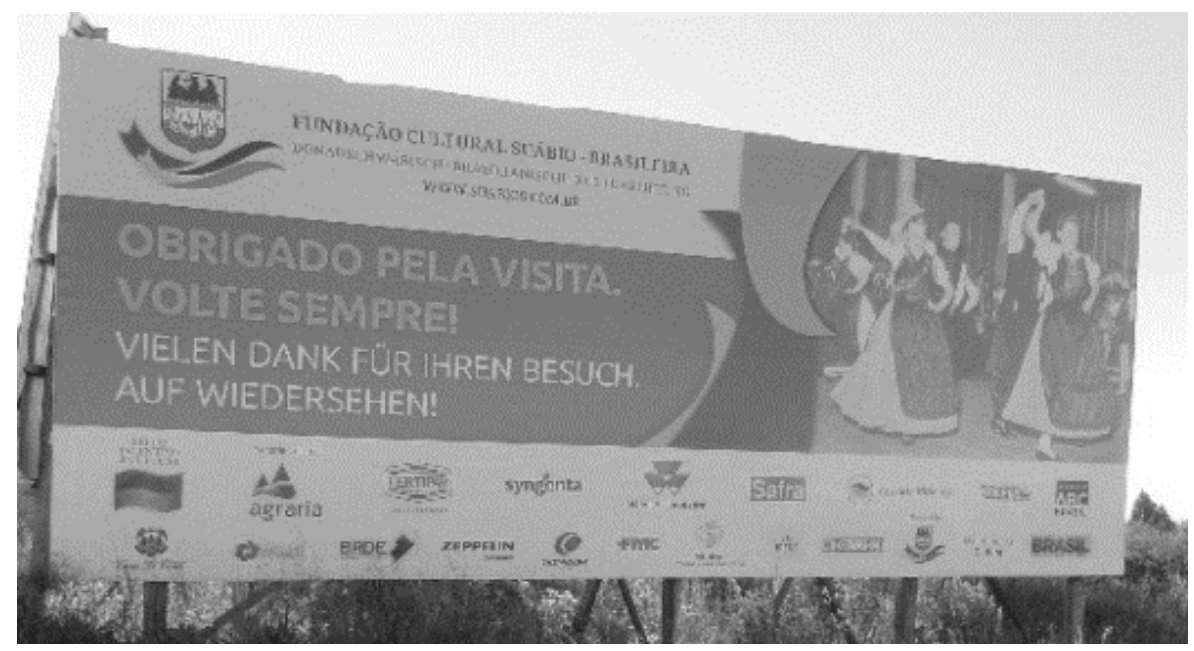

Figura 4. Placa de saída de Entre Rios (Fonte: acervo pessoal)

O uso dessas línguas em espaço público trabalha na construção de uma identidade de grupo, ou seja, os outdoors e demais placas atuam como instrumento de política de identidade. É sintomático o entendimento do município de entorno, ao considerar alemães os habitantes da colônia, pois talvez seja essa a identidade étnico-cultural e linguística pretendida pelo grupo. Por essa razão, os moradores de Guarapuava, por vezes, se surpreendem ao saber que, na colônia, a primeira língua de muitos não é português, nem alemão, mas sim o Schwowisch". Segundo Maher (2010), é "fundamental não perder de vista que a consciência de pertencer a uma minoria faz seus membros constantemente colocarem em questão suas próprias identidades". Nesse sentido, a autora apregoa que à medida que políticas linguísticas são implantadas pelo grupo, observa-se que o objetivo

\footnotetext{
3 Variedade de língua alemã que abriga muitos termos do alemão clássico ou "antigo" como dizem os moradores da região e termos do português, entre outras características próprias.
} 
principal não é a manipulação pura e simples da situação linguística, mas sim da identidade étnico-cultural do grupo.

Assim, as políticas linguísticas, arquitetadas e postas em prática localmente por comunidades específicas, agem diretamente nas "identidades dos falantes de uma dada língua, seja no sentido de enaltecê-las ou de denegri-las" (MAHER, 2010, p. 120). Por isso, entende-se, com amparo em Maher (2013), que o estabelecimento de políticas linguísticas não é um processo neutro, apolítico ou isento de conflito. Para a pesquisadora, é preciso considerar as relações de tensão traduzidas "no dilema entre, por um lado, a necessidade de promover a língua dos falantes de maior prestígio, de forma a assegurar o direito às vantagens sociais e econômicas que isso pode acarretar e, por outro, assegurar a alteridade dos falantes de línguas desprestigiadas" (MAHER, 2013, p. 121).

No caso da colônia Entre Rios, são usadas em espaços públicos duas línguas de prestígio, português e Hochdeutsch, e essa escolha promove uma identidade construída pelo grupo, a de brasileiros descendentes de alemães, ao mesmo tempo em que apaga a variedade local Schwowisch, assim como invisibiliza as ascendências específicas do grupo. Por esse viés, Hamel (2003) afirma que é possível dizer que as escolhas em termos de políticas linguísticas estão postas dentro das relações de poder e de forças simbólicas, podendo ser interpretadas unicamente por meio delas. A partir dessas forças, um espaço que é plurilíngue passa a ser caracterizado como bilíngue na/pela paisagem linguística, nas placas oficiais.

Um reflexo das escolhas linguísticas da comunidade relaciona-se ao uso do Hochdeutsch mesclado ao português em placas de estabelecimentos comerciais, principalmente na colônia Vitória, onde fica o centro econômico e comercial de Entre Rios. Nas placas oficiais, não há mescla de línguas, como visto anteriormente, porém, nas placas de estabelecimentos particulares, ocorre a mistura das duas línguas. Em seguida, há alguns exemplos de nomes de comércios, cafés e outros serviços, grafados em alemão mesclado de alguma forma ao português. 


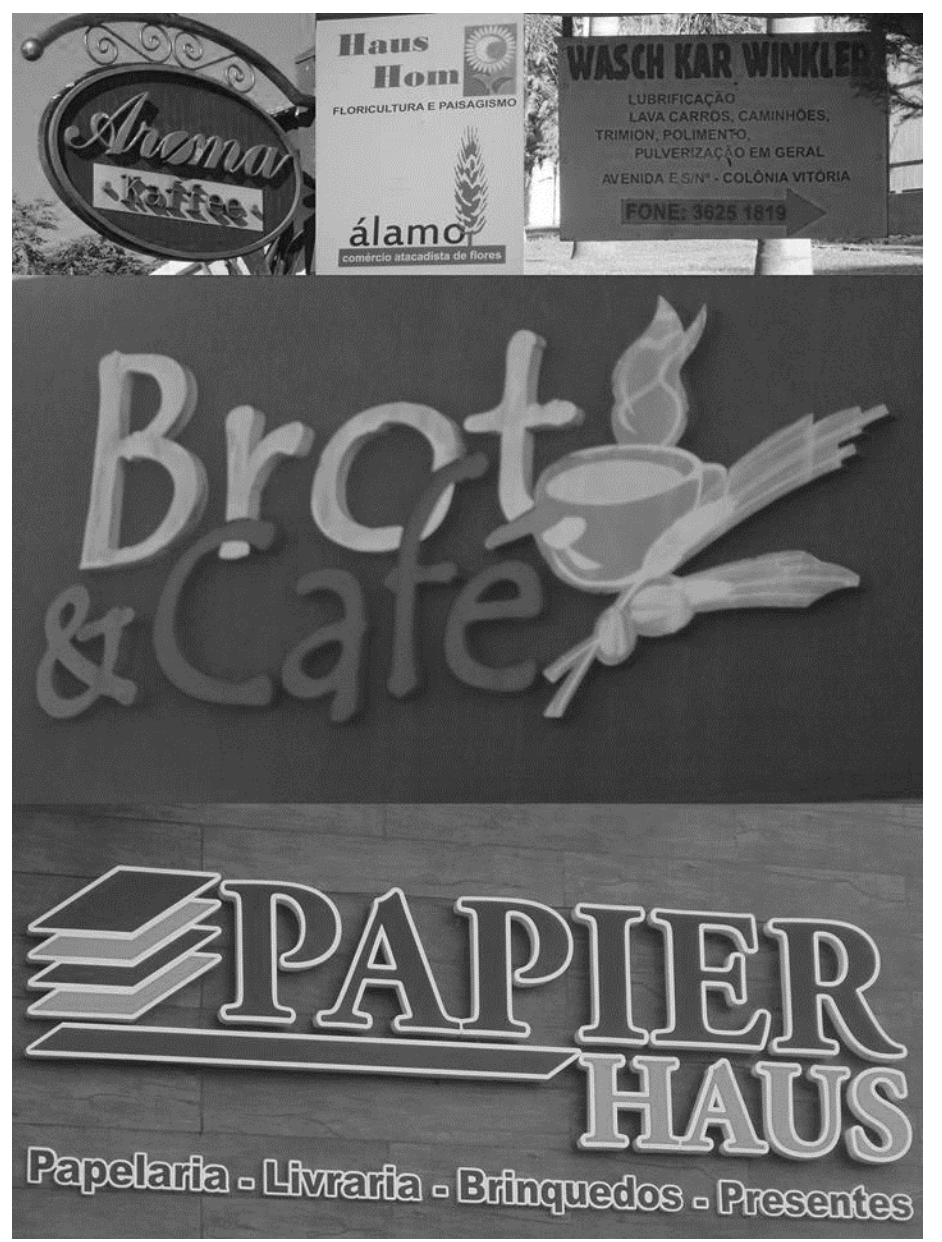

Figura 5. Placas de estabelecimentos comerciais de Entre Rios (Fonte: acervo pessoal)

A figura 5 traz imagens de cinco estabelecimentos: 1-Aroma Kaffee (Kaffee significa café); 2- Haus Hom (Haus significa casa; Hom palavra de origem desconhecida que não designa sobrenome); 3- Wasch Kar Winkler (Wasch faz referência a Wäschen, lavar em alemão; Kar refere-se possivelmente à palavra inglesa car; e Winkler é o sobrenome do proprietário); Brot \& Café (Brot significa pão); Papier Haus (a expressão significa Casa do Papel). É importante salientar que os nomes dos locais citados são escolhas dos proprietários que utilizam palavras do Hochdeutsch em construções típicas do processo de nomear em português. No caso de Papier Haus, a expressão segue a orientação do Hochdeutsch para indicação de posse (inverte a estrutura comum no português).

Nessas construções, é importante comentar que o uso do Hochdeutsch, em muitos momentos, é alterado pela influência do português. Por exemplo, em alemão, o lugar onde se serve café é designado como Café e o líquido é Kaffee, mas, nos nomes dos estabelecimentos, há uma inversão do uso dessas palavras: em Brot \& Café, para se referir a pão e café, em Hochdeutsch seria Brot \& Kaffee; em Aroma Kaffee, que parece se referir ao local, em Hochdeutsch, deveria ser Aroma Café. Sobre a expressão Haus Hom invertese a ordem original do alemão padrão, em que a designação viria antes como em Papier Haus. Pelas informações que circulam em Entre Rios, a expressão utiliza uma palavra em alemão e outra, embora de origem desconhecida, que juntas gerariam o sentido de casa em equilíbrio.

O caso de Wasch Kar Winkler também é bastante singular, pois é uma expressão que usa o Hochdeutsch, mas em uma construção portuguesa muito comum. Para dizer 
lava-car ${ }^{4}$, ao invés de usar Autowäsche, optou-se pelo verbo em Hochdeutsch, grafado sem o trema no $a$ como deveria ser, acompanhado de Kar, que não é uma palavra alemã, nem portuguesa, pelo que parece, trata-se de uma referência a car, do inglês, grafado com $k$, letra utilizada para representar o som $[k]$ em alemão. Nessa expressão, cabe ressaltar, é mantida a estrutura em português, primeiro o verbo para depois vir o substantivo, em alemão seria o contrário (como em Autowäsche), primeiro o substantivo (Auto = carro), depois o verbo (wäsch = lavar). Ao fazer essas observações, não queremos mostrar erros no uso do alemão padrão, mas evidenciar a interessante escolha que os proprietários fizeram para usar o Hochdeutsch, mantendo-o presente em seus estabelecimentos.

A partir dos exemplos, notamos que a política linguística oficial do local que valoriza o português e o Hochdeutsch influencia a construção de nomes para os estabelecimentos comerciais. Não temos comércios denominados em Schwowisch, embora esta seja uma língua bastante usada entre os descendentes. Ou seja, retomando o comentário anterior, a paisagem linguística tem sua função enquanto instrumento de política linguística, que atua sobre a construção da identidade étnica e linguística do grupo de forma simbólica. Portanto, fortalece-se a identidade étnico-linguística alemã por meio do Hochdeutsch e outra brasileira por meio do português escrito. Outras identidades, como o Schwowisch e a variedade de língua portuguesa falada pelos suábios, estão presentes na colônia, porém são sustentadas pelo viver local, por meio do falar local, pois a paisagem linguística não contempla essas ocorrências. Na escrita em espaço público, não se evidencia o plurilinguismo e, sim, o bilinguismo português/Hochdeutsch, em função de esta ser a ocorrência de prestígio e que talvez é esperada pela comunidade.

\section{Considerações finais}

Com esta discussão, procuramos compreender o modo como as línguas são disponibilizadas e representadas em espaços públicos da colônia Entre Rios, demonstrando que a paisagem linguística local é um instrumento para tornar as línguas em contato (Hochdeutsch e português) visíveis. Há a valorização do bilinguismo Hochdeutsch/português e um apagamento do plurilinguismo Schwowisch/português/Hochdeutsch. Isso ocorre porque o Schwowisch não está presente nas práticas escritas em espaço público, ficando reservado a práticas informais de interação oral entre familiares e amigos.

Desse modo, é possível dizer que a presença ou a ausência de determinadas línguas na paisagem indicam a relação entre as línguas usadas pela população, mostrando qual tem mais poder e o status que cada uma angaria. Na colônia estudada, as línguas majoritárias, a julgar apenas pela paisagem linguística, são o português e o Hochdeutsch e, por essa ação, o Schwowisch é considerada a língua minoritária, de pouco prestígio por não aparecer de modo escrito nesse cenário. Essas escolhas são reflexos das políticas linguísticas adotadas pela comunidade, postas em prática pela cooperativa dos suábios do Danúbio, as quais influenciam diretamente na identidade dos moradores da região, que, ao escolherem nomes para seus estabelecimentos, mantêm o Hochdeutsch presente.

Essa configuração da paisagem linguística fortalece pelo menos duas identidades étnico-linguísticas: alemã, por meio do Hochdeutsch e outra brasileira pelo uso do português. Isso faz com que a colônia de Entre Rios seja considerada alemã pelo munícipio que a abriga, o que parece ser um objetivo dos suábios do Danúbio em função

\footnotetext{
4 Palavra usada, com essa grafia ou como "lava car", no interior do Paraná para designar os estabelecimentos que se ocupam de lavagem de automóveis.
} 
do seu vínculo econômico com a Alemanha. Embora haja outras identidades presentes na colônia, sustentadas pelo viver local, por meio do falar local, o Schwowisch e a variedade de língua portuguesa falada pelos suábios não estão contempladas nas ocorrências escritas da paisagem linguística da região. Assim reafirmamos que as políticas linguísticas são também políticas de identidade, no sentido de que embora não fosse um objetivo da comunidade influenciar a construção da identidade étnico-cultural com a paisagem linguística, um processo não se dissocia do outro.

\section{REFERÊNCIAS}

ASSIS-PETERSON, A. A. Como ser feliz no meio de anglicismos: processos transglóssicos e transculturais. Trab. Ling. Aplic., Campinas, 47(2), p. 323-340, jul./dez. 2008.

BLOMMAERT, J. A sociolinguistics of globalization. Cambridge University Press: 2010, $231 \mathrm{p}$.

Chronicles of complexity: Ethnography, superdiversity, and linguistic landscapes. Bristol: Multilingual matters, 2012. 150 p.

Further notes on sociolinguistic scales. London: Working Papers Urban Language \& Literacies, 2006. 8 p.

BLOMMAERT, J.; MALY, I. Ethnographic linguistic landscape analysis and social change: A case study. Tilburg papers in culture studies. Paper 100, June 2014.

CAVALCANTI, M.C. Estudos sobre educação bilíngue e escolarização em contextos de minorias linguísticas no Brasil. DELTA, v. 15, p. 385-417, 1999.

Línguas ilegítimas em uma visão ampliada de educação linguística. In: ZILLES, A. M. S.; FARACO, C. A. (org.). Pedagogia da variação linguística: língua, diversidade e ensino. São Paulo: Parábola, 2015. p. 287-302.

CENOZ, J.; GORTER, D. Linguistic Landscape as an additional source of input in second language acquisition, IRAL, International Review of Applied Linguistics in Language Teaching, 46, p. 257-276, 2008 a.

. Knowledge about language and linguistic landscape. In: CENOZ, J.; HORNBERGER, N. H. (eds). Encyclopedia of Language and Education, 2nd Edition, v. 6: Knowledge about Language, p. 1-13, 2008b.

Linguistic Landscape and Minority Languages. International Journal of Multilingualism. v. 3, n. 1, 2006.

DALLA VECCHIA, A. Politicas linguísticas na Colônia “alemã" de Entre Rios: o papel do Colégio Imperatriz Dona Leopoldina. 2013. 187 f. Dissertação (Mestrado em Linguagem, Identidade e Subjetividade.) - Universidade Estadual de Ponta Grossa, Pronta Grossa, 2013.

ELFES, A. Suábios no Paraná. Curitiba: Banco Lar Brasileiro S.A., 1971. 115 p.

HAMEL, R. E. Directos Linguísticos como Directos Humanos: debates e perspectivas. In: OLIVEIRA, G. M. (org.). Declaração Universal dos Direitos Linguísticos - Novas perspectivas em Políticas Linguísticas. Campinas: Mercado de Letras; Florianópolis: IPOL, 2003. p. 47-80. 
JACQUEMET, M. Transidiomatic practices: Language and power in the age of globalization. Language \& Communication, v. 25, Issue 3, p. 257-277, July 2005.

MAHER, T. M. Ser Professor Sendo Índio: Questões de Lingua(gem) e Identidade. 1996. 261 f. Tese (Doutorado em Linguística) - Instituto de Estudos da Linguagem, Universidade Estadual de Campinas.

Políticas linguísticas e políticas de identidade: currículo e representações de professores indígenas na Amazônia ocidental brasileira. Currículo sem Fronteiras, v. 10, n. 1, p. 33-48, jan./jun. 2010.

Ecos de resistência: políticas linguísticas e línguas minoritárias no Brasil. In: NICOLAIDES, C. et al. (orgs.). Política e políticas linguísticas. Campinas: Pontes Editores, 2013. p.117-134.

OLIVEIRA, G. M. As línguas Brasileiras e os Direitos Linguísticos. In: OLIVEIRA, G. M. (org.). Declaração dos Direitos Linguísticos - Novas Perspectivas em Políticas Linguísticas. Campinas: Mercado de Letras, ALB; Florianópolis: IPOL, 2003 . p. 7-12.

OLIVEIRA, K. P. O comportamento linguístico da comunidade de Entre Rios: identidade, prestígio e estigma linguístico. Ponta Grossa: UEPG, 2013. 60 p.

PERES, E. P. Aspectos da imigração italiana no Espírito Santo: a língua e cultura do Vêneto em Araguaia. Dimensões - Revista de História, v. 26, p. 44-59, 2011 a.

Análise da vitalidade do vêneto em uma comunidade de imigrantes italianos no Espírito Santo. Revista (Con)textos linguísticos, Vitória, v. 5, p. 83-100, 2011 b.

SHOHAMY, E. Linguística Landscape and Multilingualism. In: MARTIN-JONES, M.; BLACKLEDGE, A.; CREESE, A. (org.). The Routledge of Multilingualism. Londres/Nova Yorque: Routledge, 2012. p. 538-551.

STEIN, M. O oitavo dia: produção de sentidos identitários na Colônia Entre Rios-Pr. Guarapuava: UNICENTRO, 2011.288 p.

VERTOVEC, S. Super-diversity and its implications. Ethnic and Racial Studies, v. 30, n. 6, p. 1024-1054, 2007.

Recebido em: 21/09/2015

Aprovado em: 31/03/2016 